\title{
Poluiçào e autopurificação do rio Negro nas cercanias de Manaus
}

\author{
Ozorio J. M. Fonseca (') \\ Julia Ignez Salem (') \\ Vera Lucia Guarim $\left({ }^{2}\right)$
}

\begin{abstract}
Resumo
São apresentados os dados coletados em um levantamento sobre a qualidade de água do rio Negro, nas proximidades da cidade de Manaus, Amazonas. Foram medidos alguns parâmetros físico-químicos, tais como temperatura, $\mathrm{pH}$, condutividade elétrica, transparência de Secchi e avaliadas as condições microbiológicas da quantidade de bactérias saprobiontes totais e coliformes totais, durante o ano de 1977. O trabalho foi realizado com coletas mensais, em nove locais ao longo do rio e em dois igarapés que margeiam a cidade, com amostragens $\in \mathrm{m}$ duas profundidades. Discutese a importância dos resultados sob o ponto de vista sanitário e ressalta-se a capacidade de autopurificação do rio.
\end{abstract}

\section{INTRODUÇÃO}

A microbiologia das águas da Amazônia tem sido pouco estudada, embora os ecossistemas aquáticos da região venham sendo investigados sistematicamente, nos últimos vinte anos por pesquisadores de várias nacionalidades. A atenção, no entanto, tem-se voltado para outros componentes da biocenose, especialmente para os parâmetros físico-químicos. Os microrganismos, apesar de sua importância, apenas obtiveram atenção de Schmidt (1969 a, b e 1970), Rai (1978 e 1979), Rai \& Hill (1978 e 1980) e Guarim (1979) .

Schmidt (1969 a) amostrou 12 pontos do rio Negro em frente à cidade de Manaus e estabeleceu valores de bacterioplancton para a área. O mesme autor (1969 b) trabalhando no lago Castanho, fez uma correlação entre o número de bactérias e algas, concluindo pela existência de "uma dinâmica muito forte de bioatividade em lagos tropicais". Em 1970, Schmidt estudou amostras de três diferentes regiões (Castanhc, Solimões e Negro) e con-

(1) - Instituto Nacional de Pesquisas da Amazônia, Manaus.

(2) - Universidade Federal de Mato Grosso, Cuiabá. cluiu que a relação entre o número de bactérias e algas era relativamente constante sem quaisquer flutuações nítidas, embora as quantidades absolutas desses organismos fossem sempre muito pequenas.

Guarim (1979) determinou a distribuição de Chromobacterium violaceum, nos vários tipos de água da bacia amazônica e atentou para a resistência desse microrganismo aos métodos de tratamento de água para consumo.

Rai (1978 e 1979), Rai \& Hill (1978 e 1980) dirigiram seus estudos para os mecanismos de "turnover" usando técnicas de isótopos radioativos, para caracterizar os tipos de água da Amozônia, usando padrões físico-químicos e microbiológicos.

O problema da poluição dos rios da região, como conseqüência da atividade urbana, ainda não tinha sido estudado. A cidade de Manaus com um crescimento populacional desordenado que atingiu 103,3\% entre 1970 e 1980 (Benchimol, 1981) e com uma infra-estrutura sanitária e urbana que não conseguiu acompanhar o mesmo índice, começa a ser atingida por problemas de poluição do rio, para onde são naturalmente canalizados os detritos urbanos.

Este trabalho apresenta os primeiros dados sistemáticos sobre o problema de poluição do rio Negro, mostrando as alterações da qualidade da água decorrentes da atividade humana na cidade de Manaus.

\section{MATERIAIS E MÉTODOS}

Foram selecionados 11 locais de coleta de amostras de água do rio Negro, sendo o de número 1 aproxımadamente $20 \mathrm{~km}$ a montante de Manaus, sem influência da cidade e o último (11), na altura do encontro do Negro 
com o Solimões, cerca de $13 \mathrm{~km}$ a juzante da cidade. (Fig. 1). Os pontos de coleta foram assim localizados :

\begin{tabular}{cl} 
Estação & \multicolumn{1}{c}{ Local } \\
1 & Pouco acima da foz do rio Tarumãzinho \\
2 & Entre a foz do Tarumãzinho e do Tarumã \\
3 & Praia da Ponta Negra \\
4 & Enseada da Compensa \\
5 & Igarapé de São Raimundo \\
6 & Em frente ao cais do porto \\
7 & Igarapé de Educandos \\
8 & Em frente à Colônia Oliveira Machado \\
9 & Em frente ao Frigomasa \\
10 & Paraná do Marapatá \\
11 & Próximo ao encontro das águas.
\end{tabular}

Nesses pontos, foi possível amostrar, durante 12 meses, (janeiro a dezembro de 1977) a área escolhida e acompanhar a variabilidade sazonal em cada local e a variação do número de microrganismos ao longo do trecho, desde as condições naturais (Estação 1) passando por toda a extensão da cidade, até o encontro das águas (Estação 11). Além da qualidade bacteriológica, foram registrados valores de $\mathrm{pH}$, condutibilidade elétrica e temperatura a 0 e 1 metro de profundidade. Foram também realizadas medidas de transparência da água.

As amostras foram colhidas com coletor van Dorn e separadas em frascos de vidro, previamente esterilizados, para microbiologia e em recipientes de polietiieno, de um litro de capacidade. para as medidas de potencial hidrogeniônico e condutância elétrica. A temperatura foi medida no próprio coletor.

O método microbiológico adotado foi o de filtraçãu em filtros de membrana. Para coliformes totais, foi usado o filtro Sartorius de nitrato de celulose, $0,45 \mu \mathrm{m}$ de porosidade, pelos quais eram filtradas alíquotas de 0,1 e $1,0 \mathrm{ml}$ de cadà amostra, diluidos em $15 \mathrm{ml}$ de água destilada estéril. Em seguida os filtros eram colocados sobre o meio ENDO- agar (Difco) em placas de Petri e incubados por 48 horas a $35^{\circ} \mathrm{C}$. As colônias de bactérias saprobiontes totais fcram contadas em filtros de membrana de nitrato de celulose, Sartorius, com 0,2 um de porosidade, após incubação por 24 horas a $37^{\circ} \mathrm{C}$ a partir de alíquotas de 0,1 e $1,0 \mathrm{ml}$ da

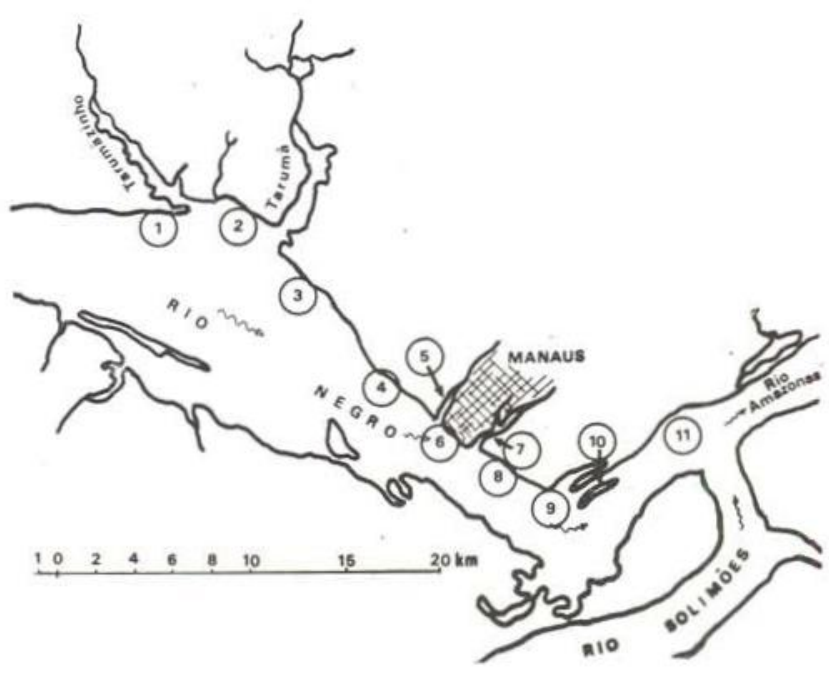

Fig. 1 - Locais de coleta.

amostra, utilizando, para cultivo, o meio Standard recomendado pela APHA (1976).

$\mathrm{O} \mathrm{pH}$ foi determinado em potenciômetro Sargent Welch, modelo LS; a condutibilidade elétrica foi medida em condutímetro Wiss. Techn. Werkstattën (WTW) modelo L.F 54 e as medidas convertidas para $20^{\circ} \mathrm{C}$; a temperatura foi tomada com termômetro colunar de mercúrio, escala 0 a $45^{\circ} \mathrm{C}$, com intervalos de $0,19 \mathrm{C}$; a transparência foi medida com disco de Secchi de $25 \mathrm{~cm}$ de diâmetro.

\section{Resultados}

O rio Negro tem uma pequena variação anual de temperatura nas profundidades estudadas, exibindo uma amplitude térmica de 28,0 a $34,6^{\circ} \mathrm{C}$, com média anual, para as duas profundidades de $30,6^{\circ} \mathrm{C}$. Não há também diferenças significativas entre 0 e 1 metro, tendo sido encontrada, na água superficial, uma média de $30.7^{\circ} \mathrm{C}(\mathrm{s}=1,30)$ e a 1 metro o valor médio alcançou $30,5^{\circ} \mathrm{C} \quad(s=1,34)$. Dos 132 perfis, $65(49,2 \%)$ apresentaram temperaturas iguais a 0 e $1 \mathrm{~m}$, e $41(31,1 \%)$, mostraram diferenças entre 0,1 e $0,5^{\circ} \mathrm{C}$.

A transparência mostrou, no rio, variações de 0,8 a $1,7 \mathrm{~m}$. Nos igarapés de São Raimundo e Educandos, esses valores vão de $0,2 \mathrm{~m}$, na época de água baixa, até $1,0 \mathrm{~m}$ quando, pela subida do nível do rio, o Negro penetra nesses afluentes. 
$0 \mathrm{pH}$ das amostras estudadas variou de 4,8 a 7,8 , distinguindo-se os valores mais baixos para o rio $(\bar{x}=5,6)$ e as mais altos para os igarapés ( $\bar{x}=6,5$ ) (Fig. 2). Há uma diferença, no entanto, dos valores desse parâmetro entre o periodo da enchente e da vazante. $\mathrm{Na}$ subida das águas (janeiro a junho), o pH médio de todas as amostras foi de 5,3 enquanto na descida (julho a dezembro) a média foi de 6,2. Essa característica é observada tanto no rio como nos igarapés, sendo que os três primeiros meses de vazante (julho a setembro), apresentam os valores mais altos. Assim é que, nesse período, o $\mathrm{pH}$ médio do rio atinge 6,5 , do igarapé de São Raimundo alcança 7,2 e o de Educandos chega a 7,4 .

A condutividade elétrica é normalmente baixa no rio Negro como conseqüência da baixa concentração de eletrólitos. Os valores encontradcs, nesse trabalho, vão de 5,8 a 12,2 $\mathrm{uS}_{20} \cdot \mathrm{cm}^{-1}$, na água do rio, de 13,7 a 68,6 $\mathrm{uS}_{20} \cdot \mathrm{cm}^{-1}$, no igarapé de São Raimundo e de 8,3 a $126,1 \mathrm{uS}_{20} . \mathrm{cm}^{-1}$, no igarapé de Educandos (Gráfico 1). A média encontrada para as amostras coletadas no rio foi de $8,4 \mathrm{uS}_{20} . \mathrm{cm}^{-1}$ enquanto os igarapés mostraram o valor de 45,5 $\mathrm{uS}_{2 \mathrm{~s}} . \mathrm{cm}^{-1}$, tendo o igarapé de Educandos um valor médio superior ao de São Raimundo.

As bactérias totais são aqui consideradas como as capazes de crescer no meio de cultura utilizado sob as condições descritas em Materiais e Métodos. Evidenciam-se, na Tabela I, alterações extremamente grandes, no número desses organisrnos, por unidade amostrada, variando de 1 a 37.170 colônias $/ \mathrm{ml}$. A menor quantidade observada foi na estação 1 , a $0 \mathrm{~m}$. no mês de fevereiro e a maior na estação 9 . a $0 ! n$, em novembro. As estações 5,7 e 9 são as de maior número de bactéras totais (Tabela 1, Gráfico 2) com médias anuais de 3447,3317 e 2916 colônias/ml, respectivamente. É importante ressaltar também que, no período da enchente, o número -de bactérias saprobiontes é 4,5 vezes inferior à média desses organismos, nas amostras coletadas no período de vazante.

Para os coliformes totais, os resultados mostrados, na Tabela II, apresentam uma variação bastante acentuada no número de organismos $/ \mathrm{ml}$, e evidenciam alguns pontos críticos de qualidade da água. Há uma nítida influência da época do ano sobre a quantidade desses microrganismos. Na enchente, a média das 11 estações é de 89 colônias/ml, enquanto na vazante, essa medida ascende para 445 colônias $/ \mathrm{ml}$, exatamente 5 vezes maior que no período anterior. As estações 4,5 e 7 são as de maior índice, com médias anuais de 714 . 630 e 637 colônias $/ \mathrm{ml}$, respectivamente, enquanto a estação 3 é a que apresenta a menor média com apenas 29 colônias/ml. A amplitude de variação vai de 0 a 8690 colônias $/ \mathrm{ml}$. com ausência de coliformes em 14 das 2.64 amostras estudadas $(5,3 \%)$, sendo que no mês de fevereiro, das 22 amostras dos 11 perfis, $10(45,4 \%)$ foram negativas para esse indicador. O maior índice encontrado foi na estação 4 a 0 metro, no mês de novembro.

\section{DISCUSSÃo}

Na região estudada, não há grande variações térmicas. É claro que algumas diferenças significativas puderam ser observadas, principalmente nas camadas superiores mais sujeitas a alterações climáticas bruscas tais como
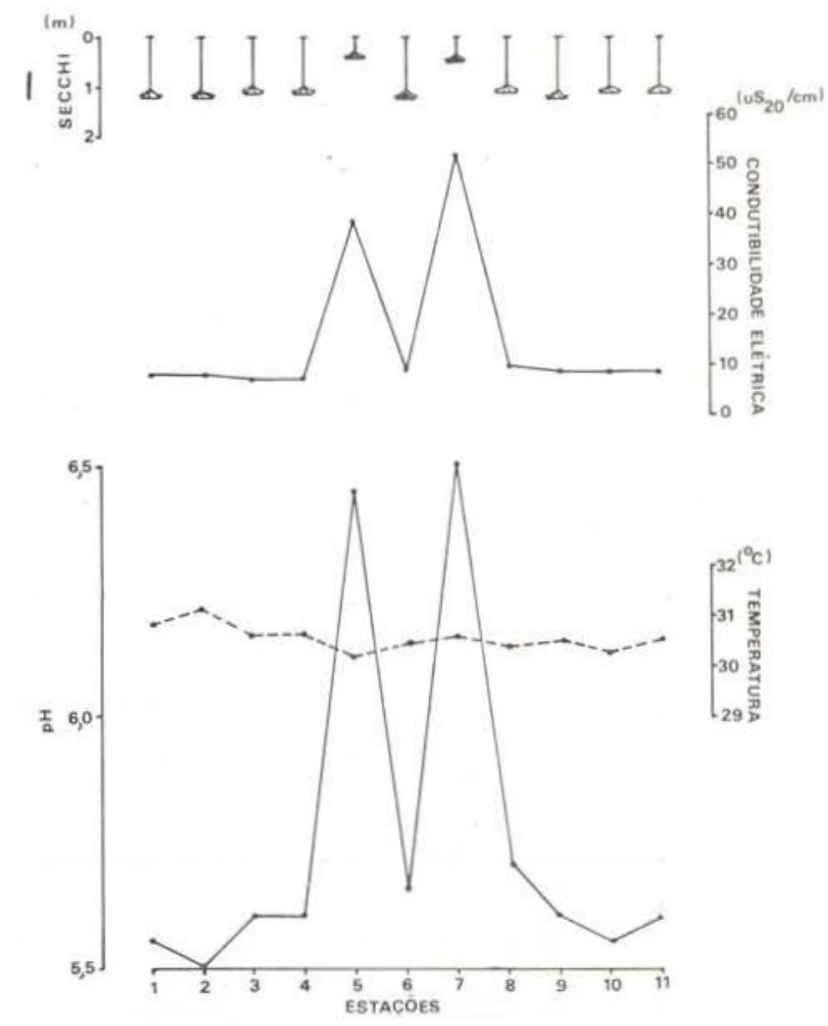

Fig. 2 - Gráfico dos fatores abióticos (média anual) nas 11 estaçōes (jan-dez 77). 
TABELA I - Número de colônias/ml de bactérias totais nas amostras de água das estações de coleta (jan-dez, 1977).

\begin{tabular}{|c|c|c|c|c|c|c|c|c|c|c|c|c|c|c|}
\hline \multirow{2}{*}{ Estaçōes } & \multirow{2}{*}{$\begin{array}{c}\text { Prof. } \\
\text { m }\end{array}$} & \multicolumn{12}{|c|}{ MESES } & \multirow{2}{*}{$\bar{x}$} \\
\hline & & $\mathrm{J}$ & $\mathrm{F}$ & $M$ & A & $M$ & $\mathrm{~J}$ & $\mathrm{~J}$ & A & S & 0 & $\mathrm{~N}$ & D & \\
\hline \multirow[b]{2}{*}{1} & 0 & 31 & 1 & 16 & 6 & 13 & 15 & 77 & 91 & $\ldots$ & 37 & 51 & 4480 & 438 \\
\hline & 1 & 461 & 2 & 3280 & 609 & 603 & 81 & 246 & 135 & $\ldots$ & 773 & 482 & 275 & 631 \\
\hline \multirow[b]{2}{*}{2} & 0 & 11 & 3 & 5 & 7 & 19 & 6 & 78 & 75 & 9790 & 112 & $\ldots$ & 91 & 937 \\
\hline & 1 & 34 & 3 & 356 & 108 & 304 & 14 & 245 & 144 & 13950 & 357 & $\ldots$ & 98 & 1387 \\
\hline \multirow{2}{*}{3} & 0 & 26 & 2 & 28 & 9 & 17 & 26 & 30 & 85 & 4610 & 144 & $\ldots$ & 70 & 456 \\
\hline & 1 & 96 & 12 & 108 & 3230 & 103 & 44 & 73 & 39 & 2570 & 98 & 4090 & 405 & 906 \\
\hline \multirow{2}{*}{4} & 0 & 234 & 5 & 17 & 12 & 36 & 8 & 128 & 367 & $\ldots$ & 34 & 14430 & 400 & 1425 \\
\hline & 1 & 96 & 11 & 116 & 1666 & 190 & 123 & 63 & 147 & $\ldots$ & 37 & $\ldots$ & 1276 & 372 \\
\hline \multirow{2}{*}{5} & 0 & $\ldots$ & 570 & 1890 & 6200 & 598 & 3340 & 343 & 807 & 7800 & 1170 & 8680 & 760 & 2923 \\
\hline & 1 & $\ldots$ & 3590 & 1760 & 8300 & 725 & $\ldots$ & 283 & 490 & $\ldots$ & 3560 & 3540 & 13500 & 3972 \\
\hline \multirow[b]{2}{*}{6} & 0 & 139 & 13 & 49 & 22 & 40 & 64 & 86 & 533 & 6940 & 42 & $\ldots$ & 284 & 746 \\
\hline & 1 & 146 & 13 & 219 & 4560 & 143 & 46 & 66 & 317 & 1219 & 71 & $\ldots$ & 128 & 630 \\
\hline \multirow{2}{*}{7} & 0 & $\ldots$ & 4130 & 151 & 4140 & 521 & 2880 & 791 & 1192 & $\ldots$ & 8790 & $\ldots$ & 1542 & 2682 \\
\hline & 1 & $\ldots$ & 6250 & 181 & 3240 & 499 & 119 & 631 & 10980 & 9840 & 6450 & $\ldots$ & 1344 & 3953 \\
\hline \multirow{2}{*}{8} & 0 & 221 & 18 & 72 & 74 & 203 & 8 & 163 & 52 & 1275 & 460 & 1224 & 2970 & 562 \\
\hline & 1 & 119 & 24 & 188 & 5460 & 247 & 1170 & 327 & 133 & 9400 & 560 & 9240 & 1460 & 2361 \\
\hline \multirow{2}{*}{9} & 0 & 218 & 19 & 154 & 140 & 61 & 113 & 97 & 229 & 1961 & 38 & 37170 & 213 & 3368 \\
\hline & 1 & 319 & 17 & 97 & 711 & 167 & 290 & 118 & 4470 & 1159 & 189 & 20580 & 1452 & 2464 \\
\hline \multirow{2}{*}{10} & 0 & 150 & 12 & 199 & 107 & 65 & 40 & $\{37$ & 73 & 481 & 567 & 4130 & 1360 & 610 \\
\hline & 1 & 96 & 6 & 230 & 804 & 492 & 330 & 141 & 334 & 541 & 318 & 3658 & 236 & 602 \\
\hline \multirow{2}{*}{11} & 0 & 26 & 13 & 13 & 27 & 15 & 23 & 26 & 49 & 137 & 96 & 834 & 121 & 115 \\
\hline & 1 & 60 & 25 & 153 & 325 & 212 & 54 & 40 & 50 & 200 & 209 & 15990 & 1010 & 1527 \\
\hline \multirow{2}{*}{$\bar{x}$} & 0 & 177 & 435 & 236 & 977 & 144 & 593 & 178 & 323 & 4124 & 1042 & 9503 & 1117 & - \\
\hline & 1 & 159 & 905 & 608 & 2637 & 335 & 227 & 203 & 1567 & 4815 & 1147 & 8231 & 1926 & - \\
\hline
\end{tabular}


frentes frias e tempestades. A isotermia, no entanto, é uma característica das águas da região, em função da pequena variação climática. Uma poluicãa térmica oriunda das águas de resfriamento das caldeiras industriais situadas às margens dos cursos de água, não pode ser detectada.

No que diz respeito à transparência, os igarapés de São Raimundo e Educandos são os locais mais afetados. Sendo em suas origens semelhantes a todos os igarapés de floresta, com grande quantidade de material húmico em suspensão, recebem, no baixo curso, uma carga tâo grande cie detritos, que sua transparência mais se assemelha aos corpos de água do tipo "branco" (Fig. 2).

A saida de água do igarapé de Educandos, associado à descarga das populações ribeirinhas, permitiu o registro de valores altos de $\mathrm{pH}$ no rio Negro, na época da vazante. Esse fato pode ser entendido pela retirada do material acumulado junto à margem e dentro do igarapé na época de água atla, e que é carreado para o curso d'água principal, à medida que o nível desce, sendo levado pela corrente, pela região ribeirinha que é exatamente a zona utilizada para amostragem.

A condutividade elétrica é muito alta nos igarapés, ultrapassando os valores normalmente encontrados para o médio Amazonas que vão de 44,8 a 82,8 uS $_{20} . \mathrm{cm}^{-1}$ (Schmidt, 1972). Usando os fatores de multiplicação de Richard \& Van Cu (1961), para cálculo de minerais totais, a partir da condutividade elétrica, ter-se-ia uma variação, nos igarapés, de 11,3 a $119,5 \mathrm{mg} / 1$, representando um aumento de quase 10 vezes na quantidade de sólidos totais dissclvidos, entre o mínimo e o máximo. Evidentemente, esses fatores não servem para águas de haixa condutância e $\mathrm{pH}$, uma vez que em concentrações maiores de Hidrogênio, esse elemento passa a agir como condutor, conforme demonstrado por Leenheer \& Santos (1980). Entretanto, os valores mais altos desse parâmetro são os de maior significação, dentro do objetivo desse trabalho, por destacarem as alteraçōes que são tão mais importantes, por ser o igarapé de Educandos, um habitat de Biomphalaria amazonica, um bom vetor poten-

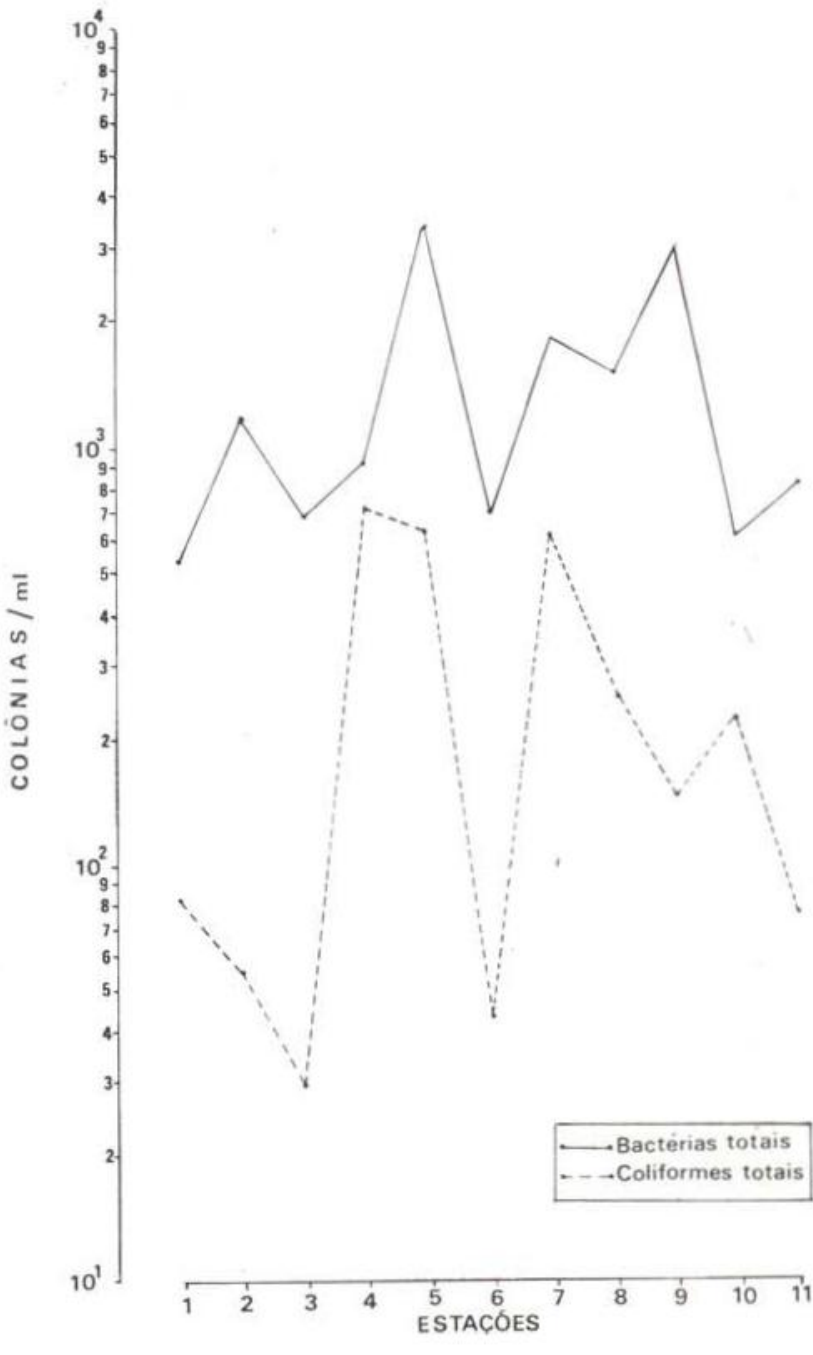

Fig. 3- Gráfico da média anual do número de bacté rias nas 11 estaçōes (jan-dez 77).

cial da esquistossomose (Correa \& Paraense, 1971).

Do ponto de vista microbiológico, a área estudada apresenta algumas peculiaridades que são traduzidas nos resultados encontrados. A estação 4 está localizada a montante da tomada de água da cidade e recebe sua carga de poluentes de um pequeno córrego que, atravessando parte do bairro da Compensa. carrega para o rio os dejetos dessa população que constrói seus sanitários sobre o pequeno curso de água. O fato de a captação de água para tratamento e distribuição ser feita por tubos situados em regiōes mais profundas, não impossibilita a sucção de, pelo menos, parte da massa contaminada, tornando a purificação 
TABELA II - Número de colônias/ml de coliformes totais nas amostras de água das estações de c leta (jan-dez, 1977).

\begin{tabular}{|c|c|c|c|c|c|c|c|c|c|c|c|c|c|c|}
\hline \multirow{2}{*}{ Estações } & \multirow{2}{*}{$\begin{array}{c}\text { Prof. } \\
\text { m }\end{array}$} & \multicolumn{12}{|c|}{ MESES } & \multirow{2}{*}{$\bar{x}$} \\
\hline & & J & $\mathrm{F}$ & M & A & M & $\mathrm{J}$ & J & A & s & $\mathrm{O}$ & $\mathrm{N}$ & D & \\
\hline \multirow{2}{*}{1} & 0 & 3 & 0 & 0 & 3 & 24 & 24 & 7 & 146 & 79 & 55 & $\ldots$ & 5 & 31 \\
\hline & 1 & 114 & 0 & 56 & 1 & 480 & 83 & 47 & 193 & 230 & 153 & 55 & 137 & 129 \\
\hline \multirow{2}{*}{2} & 0 & 2 & 0 & 1 & 12 & 26 & 16 & 33 & 68 & 120 & 20 & 9 & 27 & 28 \\
\hline & 1 & 11 & 0 & 124 & 5 & 251 & 32 & 59 & 261 & 18 & 25 & 39 & 172 & 83 \\
\hline \multirow{2}{*}{3} & 0 & 0 & 0 & 6 & 0 & 26 & 22 & 25 & 99 & 29 & 6 & 19 & 16 & 21 \\
\hline & 1 & 10 & 0 & 123 & 3 & 33 & 28 & 23 & 52 & 28 & 23 & 4 & 144 & 38 \\
\hline \multirow{2}{*}{4} & 0 & 53 & 70 & 3 & 18 & 7 & 1 & 34 & 401 & 4240 & 28 & 8690 & 403 & 1126 \\
\hline & 1 & 25 & 108 & 5 & 146 & 90 & 54 & 33 & 113 & 2260 & 34 & 87 & 665 & 302 \\
\hline \multirow{2}{*}{5} & 0 & 278 & 1320 & 162 & 108 & 140 & 160 & 102 & 378 & 282 & 820 & 460 & 2800 & 584 \\
\hline & 1 & 325 & 670 & 147 & 15 & 168 & 670 & 149 & 233 & 1460 & 780 & 473 & 3040 & 677 \\
\hline \multirow{2}{*}{6} & 0 & 53 & 0 & 11 & 33 & 13 & 20 & 29 & 76 & 59 & 40 & 83 & 13 & 36 \\
\hline & 1 & 40 & 2 & 55 & 18 & 12 & 17 & 26 & 86 & 81 & 25 & 104 & 132 & 50 \\
\hline \multirow{2}{*}{7} & 0 & 330 & 2220 & 59 & 3 & 302 & 240 & 232 & 229 & 348 & 730 & 4570 & 486 & 812 \\
\hline & 1 & 260 & $\ldots$ & 60 & 0 & 194 & 23 & 230 & 256 & 227 & 185 & 3580 & 84 & 463 \\
\hline \multirow{2}{*}{8} & 0 & 56 & 25 & 54 & 11 & 85 & 85 & 78 & 108 & 267 & 76 & 579 & 302 & 144 \\
\hline & 1 & 14 & 32 & 53 & 6 & 130 & 15 & 34 & 131 & 1350 & 330 & $\ldots$ & 2040 & 376 \\
\hline \multirow{2}{*}{9} & 0 & 88 & 4 & 16 & 6 & 24 & 50 & 50 & 530 & 231 & 36 & 670 & 29 & 144 \\
\hline & 1 & 12 & 10 & 12 & 10 & 30 & 15 & 45 & 268 & 425 & 138 & 798 & 51 & 151 \\
\hline \multirow{2}{*}{10} & 0 & 17 & 0 & 27 & 1 & 41 & 40 & 29 & 406 & 729 & 51 & 1827 & 148 & 276 \\
\hline & 1 & 38 & 0 & 15 & 10 & 37 & 24 & 33 & 80 & 340 & 41 & 1385 & 195 & 183 \\
\hline \multirow{2}{*}{11} & 0 & 1 & 4 & 6 & 17 & 19 & 51 & 6 & 58 & 80 & 31 & 285 & 56 & 51 \\
\hline & 1 & 9 & 0 & 12 & 29 & 14 & 5 & 14 & 53 & 86 & 36 & 785 & 228 & 106 \\
\hline \multirow{2}{*}{$\bar{x}$} & 0 & 80 & 331 & 31 & 19 & 64 & 64 & 57 & 228 & 588 & 172 & 1819 & 389 & - \\
\hline & 1 & 78 & 82 & 60 & 22 & 131 & 88 & 63 & 157 & 590 & 161 & 731 & 626 & - \\
\hline
\end{tabular}


mais onerosa. A estação 5 recebe vários cursos de água que atravessam a cidade, no sentido leste-oeste e norte-sul, pela periferia, sendo um deles o igarapé do Parque 10 onde é despejada a água servida de vários conjuntos habitacionais. O igarapé de Educandos recebe o efluente de algumas indústrias e é habitado em suas margens por numerosa população constituída de famílias de baixa renda que habitam casas sobre palafitas e que drenam todo o produto da vida doméstica para esse curso de água.

Os resultados revelam apenas uma parte do problema de poluição dos cursos de água em Manaus. Levantamentos que incluam aspectos virais, protozoológicos e helmintológicos precisam ser realizados, no sentido de fornecer subsídios mais amplos para avaliação total das conseqüências advindas das alterações da qualidade de água sobre a população humana,

No aspecto de bactérias patogênicas, sabe-se que há uma estabilidade considerável na relação " $\mathrm{n}$ o de Salmonella typhi $/ \mathrm{n}$. $^{0}$ de coliformes", em águas poluídas por dejetos domésticos de populações suficientemente grandes para abrigarem indivíduos com doenças causadas por bactérias patogênicas intestinais ou portadores destas (Kehr \& Butterfield, 1943). Assim, enquanto a água contiver algum coliforme, terá toda a probabilidade de também conter bactéria patogênica. Geldrich (1970) resumiu os dados de numerosos levantamentos nos Estados Unidos e demonstrou que a freqüência de isolamentos de Salmonella sobe de 27,6 para $85,2 \%$ quando a densidade de coliformes sobe de $1-200$ para $200-1000 / 100 \mathrm{ml}$ e chegando a $100 \%$ quando o número de coliformes é maior que $2000 / 100 \mathrm{ml}$.

\section{CONCLUSÃO}

Tendo em vista as conclusões de Geldrich (1970), 87,5\% das amostras coletadas nas estações 4,5 e 7 teriam $100 \%$ de probabilidade de conter bacterias do gênero Salmonella, pois possuem índices superiores a 2000 coliformes/ $100 \mathrm{ml}$.

Pela Portaria GM 0013 de 15/01/76 do Ministério do Interior do Brasil que estabele- ceu a classificação das águas interiores e normalizou os padrões de qualidade, as estações 4, 5 e 7 estariam enquadradas na classe 4 e sujeitas à interdição .

A análise dos Gráficos (Fig. 2 e 3), por outro lado, revela uma identidade nos valores dos parâmetros mensurados nas estações 1 e 11 , refletindo uma capacidade de autopurificação do rio, embora seja bastante difícil quantificar essa potencialidade. De qualquer forma, dentro das perspectivas de crescimento da cidade, as previsões são de um aumento cada vez maior dos índices de poluição, havendo o risco de scmente, "a posteriori", saber-se o quanto o rio Negro foi capaz de auto-depurar-se.

\section{SUMMARY}

This paper presents a survey of some aspects of Rio Negro water quality in the vicinity of Manaus, Amazonas, Brazil. Measurements of temperature, pH, electrical conductivity, light penetration (Secchi), saprophyte and total coliform bacteria, were carried out from January through December of 1977 . The samples were collected at two depths at eleven places along the river and from two streams at the outskirts of the town. The results are discussed from a sanitary point of view and the autopurification capacity of the river is emphasized.

\section{REFERENCIAS BIBLIOGRÁFICAS}

\section{AMERICAN PUBLIC HEALTH ASSOCIATION}

1976 - Standard methods for the examination of water and water waste. APHA, AWWA. WPCF, Washington.

BENCHIMOL, S.

1981 - Amazônia Legal na década 70/80. Expansão e concentração demográfica. CEDEAM/ UA, Manaus.

CORREA, L.R. \& PARAENSE, W.L.

1971 - Susceptibility of Biomphalaria amazonica to infection with two strains of Schistosoma mansoni. Rev. Inst. Med. Trop. São Paulo, 13: $387-390$.

GELDRICH, E.E.

1970 - Applying bacteriologicol parameters to recreational water quality. Jour. Amer. Water Work Assoc. 62: 113-121.

GUARIM, V.L.M. dos S.

1979 - Ocorrência e distribuição de Chromobacterium violaceum (Schroeter) Bergonzini 1881, na Amazônia Central. Acta Amazonica, 9 (3): 501-506. 
KEHR, R.W. \& BUTTERFIELD, C.T.

1943 - Notes on the relation between coliforms and enteric pathogens. Publ. Hith. Rep. (Wash.) 58: 589-591.

LEENHEER, J.A. \& SANTOS, U. de M.

1980 - Considerações sobre os processos de sedimentação na água preta ácida do rio $\mathrm{Ne}$ gro (Amazônia Central). Acta Amazonica, 10 (2): 343-355.

MINISTÉRIO DO INTERIOR

1976 - Portaria GM 0013 de 15/01/76. Legislação Básica, SEMA, Brasília.

RAI, $\mathrm{H}$.

1978 - Utilização de glicose por bactérias heterotróficas no ecossistema da Amazônia Central. Acta Amazonica, 8 (2): 225-232.

1979 - Microbiology of Central Amazon Lakes. Amazoniana, 6 (4): 583-599.

RAI, H. \& HILL, G.

1978 - Bacteriology studies on Amazonas, Mississipi and Nile waters. Arch. Hydrobiol. 81 (4): $445-461$.
1980 - Classification of Central Amazon lakes on the basis of their microbiological and physico-chemical characteristics. Hydrobiologia 72: 85-99,

RICHARD, C. \& VAN CU, N.

1961 - Relation entre la résistivité d'une eau et son taux de mineralization. L'eau 1: 22-24.

SCHMIDT, G.W.

$1969 a$ - Vertical distribution of bacteria and algae in a tropical lake. Int. Revue ges Hydrobiol. 54: 791-797.

$1969 \mathrm{~b}$ - Bakterienzahlen in wasser von Manaus (Amazonas) Z. Allgem. Mikrobiol. 9: 401404.

1970 - Numbers of bacteria and algae and their interrelations in some Amazonian waters. Amazoniana, 2 (4): 393-400.

1972 - Amounts of suspended solids and dissolved substances in the middle reaches of the Amazon over the course of one year. (August 1969 - July 1970). Amazoniana, 3 (2): 208-223.

(Aceito para publicação em 17/02/82) 